\title{
VARIATION OF OSL RESIDUAL DOSES IN TERMS OF COARSE AND FINE GRAIN MODERN SEDIMENTS ALONG THE HUNGARIAN SECTION OF THE DANUBE
}

\author{
ORSOLYA TÓTH $^{\mathbf{1}}$, GYÖRGY SIPOS ${ }^{\mathbf{1}}$, TÍMEA KISS ${ }^{\mathbf{1}}$ and TAMÁS BARTYIK ${ }^{\mathbf{1}}$ \\ ${ }^{I}$ Department of Physical Geography and Geoinformatics, University of Szeged, Egyetem u. 2-6, H-6722 Szeged, Hungary
}

Received 20 July 2016

Accepted 21 September 2017

\begin{abstract}
Reliable OSL dating of fluvial sediments requires an assessment of incomplete bleaching and consequent residual dose in samples. A well-established way of this is determining the equivalent dose of modern samples from similar sedimentary environments as in the case of palaeo-samples. Meanwhile, relatively low, or close to zero doses are also greatly affected by the thermal transfer phenomenon, which can also lead to a palaeodose overestimation. The present study attempts to quantify both factors in coarse and fine grain modern sediments along the Hungarian section of the Danube River, with the aim of determining their significance when dating both young and palaeosediments. Investigations were performed at 30 sites along a $417 \mathrm{~km}$ long river section with varying morphological and erosive character. The studied samples were deposited during the record flood of 2013 , mobilising and relocating a vast amount of sediment in the system. Tests have shown that thermal transfer can be minimized successfully by choosing preheat temperatures below $200^{\circ} \mathrm{C}$, however it remains a significant factor when dating young or modern sediments. Based on equivalent dose measurements, coarse grain samples proved to be relatively well bleached, and residual doses showed only a minor spatial variation. Although in terms of fine grain samples residual doses were obviously much higher, results can enhance the reliability of dates retrieved later from fine grain palaeosamples. In the meantime, the higher spatial variability of fine grain residual doses may also allow the assessment of the erosive character of different river reaches.
\end{abstract}

Keywords: OSL, modern fluvial samples, residual dose, thermal transfer, Danube.

\section{INTRODUCTION}

The successful application of optically stimulated luminescence (OSL) on young fluvial deposits requires the assessment of several factors influencing the reliability of the dating result. Residual dose $\left(\mathrm{D}_{\text {res }}\right)$ as a consequence of incomplete bleaching and thermal transfer (TT) is among

Corresponding author: G. Sipos

e-mail: gysipos@geo.u-szeged.hu the most significant issues affecting the apparent and usually overestimated age determined by the method.

The resetting or bleaching of the luminescence signal in sediment grains during transportation as a consequence of sunlight exposure is one of the most important underlying principle of OSL dating, providing the zeroing event for the analysis. Resetting is affected by several external and inherent factors, such as the length, distance, mode and recurrence of the transportation process, or the mineralogical composition and size of grains (Alexanderson, 2007; Rittenour, 2008). In fluvial environments, 
incomplete resetting and thus the preservation of a $D_{\text {res }}$ is highly probable, since travelling time before deposition can be short, the shading effect of water can be significant and grains may coagulate. Although it can be complicated, the handling of the problem is important either young or older sediments are the subject of the investigation. In most of the cases, the issue of residual dose is tackled by applying different statistical analyses on equivalent dose $\left(D_{e}\right)$ values measured preferably using single grains or very small aliquots (Olley et al., 1998; Galbraith et al., 1999; Lepper et al., 2000; Fuchs and Lang 2001; Galbraith, 2005). Another approach can be to determine residual doses in modern, known-age sediments in similar sedimentary environments to those from where palaeo-samples have been collected (Murray et al., 1995; Olley et al., 1998; Stokes et al., 2001). This way, the statistically derived minimum equivalent dose can be compared to the $\mathrm{D}_{\text {res }}$ measured directly.

In larger river systems, the degree of resetting may significantly vary, both in space and according to the sediment type (Sipos et al., 2016), therefore the analysis of longer sections and different grain sizes is desirable. Stokes et al. (2001) investigated the bedload of the Loire River along its entire $1000 \mathrm{~km}$ length. In the headwater area $\mathrm{D}_{\text {res }}$ dropped from 14.0 Gy to $3.3 \mathrm{~Gy}$, while $300 \mathrm{~km}$ further downstream it decreased to $0.3 \mathrm{~Gy}$. Similar, but somehow higher values were obtained by Jaiswal et al. (2009), investigating modern slack water deposits in the mid-section of the subtropical Kaveri River. Results indicated a $0.3-1.2$ Gy $\mathrm{D}_{\text {res}}$, meaning a 200-1000-year age overestimation. Nevertheless, as indicated by Jaiswal et al. (2009) and others as well (e.g. Rittenour, 2008), significant spatial differences may arise as a result of floods and consequent erosion of older deposits. Therefore, we suggest that the analysis of flood related sediments may indicate the possible maximum of residual doses in the sediments of a river system. Concerning the Danube, with the exception of Fiebig and Preusser (2007), hardly any investigations were made on modern sediments. During their research near the Vienna section of the river they obtained remarkably high residual doses $(6.1 \pm 0.2 \mathrm{~Gy})$, which were explained clearly by anthropogenic effects, namely the introduction of quarried sediments into the river to normalise bedload budget and prevent incision.

The significance of grain size and mineralogy in dating fluvial deposits is widely studied in the literature (see e.g. Olley et al., 1998; Wallinga et al., 2001; Colls et al., 2001; Vandenberghe et al., 2007). In general, it is claimed that the sand sized fraction (coarse grains) is much more probable to get reset adequately then the silt sized fraction (fine grains) (Hu et al., 2010, Vandenberghe et al., 2007; Alexanderson, 2007). This is explained mostly by the coagulation of fine grains during transport and deposition, whereas coarse bedload grains might be exposed to sunlight more probably on the surface of bars for example (Hu et al., 2010). Concerning mineralogy quartz is preferred, as feldspars are proven to be bleached less efficiently (Rittenour, 2008).

When determining the dose absorbed by young or modern sediments, another factor, thermal transfer (TT), may also significantly influence the results. The magnitude of overestimation can reach several grays $(\mathrm{Li}$ and $\mathrm{Li}$, 2006; Jain et al., 2004), which can even overshadow the effect of incomplete bleaching. Two types of TT are known: recuperation and basic transfer (Aitken, 1998), and both are generated by returning preheats during OSL measurements. Whereas recuperation, a combination of photo and thermal transfer effects, can be routinely monitored by using the SAR protocol, and can be mitigated by inserting a hot bleach at the end of each SAR cycle (Wintle and Murray, 2006), the estimation of basic transfer, related to heat induced charge release from lightinsensitive deep traps and subsequent retrapping in OSL traps, requires more care (Wang et al., 2006).

Based on the study of Ward et al. (2003) on several samples from different depositional environments, fluvial sediments are prone to be affected by a significant TT as a result of preheat (up to around 1.5 Gy at $220^{\circ} \mathrm{C}$ ), while aeolian samples proved to be insensitive to thermal treatment. On the other hand, Jaiswal et al. (2009) observed only a $0.04-0.10$ Gy TT in fluvial sediments. Treulsen and Wallinga (2003) examined in detail the effect of TT on different coarse grain fractions of fluvial channel deposits, and received values between $0.2-0.5 \mathrm{~Gy}$ at $200^{\circ} \mathrm{C}$, but did not find any relationship between grain size and the degree of TT.

In the present paper, coarse and fine grain river bank sediments deposited during the 2013 Danube flood along the Hungarian section of the river were investigated. The primary aim of the research was to determine the effect of thermal transfer and the degree of incomplete bleaching on both coarse and fine grain sediments. The second major aim was to investigate the longitudinal distribution of thermal transfer corrected residual doses, and to reveal whether there is any spatial pattern in the variation of values. Moreover, results can also contribute later to the assessment of age uncertainties in terms of paleosediments collected in the region.

\section{STUDY AREA AND SAMPLING}

The Danube with its $2850 \mathrm{~km}$ length, $817000 \mathrm{~km}^{2}$ large drainage basin and its versatile geological and geomorphological background is one of the most complex fluvial systems of the world. The Hungarian section of the river is $417 \mathrm{~km}$, most of which has undergone river regulation in the $19^{\text {th }}$ and $20^{\text {th }}$ centuries. Nevertheless, downstream of the Gabčíkovo hydropowerplant (1992) no dams hamper the continuity of sediment transport, therefore luminescence characteristics are determined by quasi natural processes. 
The mode of sediment transport clearly shifts on the Hungarian section. Prior to the diversion of the Danube to the Gabčíkovo plant, the discharge of the gravelly bedload was $600000 \mathrm{~m}^{3} /$ year at the entrance to the country (Bogárdi, 1971), while already after 50-70 km where the river leaves its alluvial fan it decreased to around 30000 $50000 \mathrm{~m}^{3} /$ year. In the meantime, median grain size halved (from 5-7 to $2-3 \mathrm{~cm}$ ), thus a significant amount of bedload is converted into suspended load. The sediment regime has been dramatically altered on a $50 \mathrm{~km}$ long section as a result of channel diversion to the above mentioned hydropower plant, but during larger floods connectivity is refreshed in partly abandoned anabranches as well. Going downstream the significance of suspended load is overwhelming and its discharge reaches 6-7 million t/year on the middle section of the Hungarian Danube, and 8-9 million $\mathrm{t} /$ year on its lower reach. Bedload measurements are very scarce on these sections. Bedload is mostly composed of coarse and medium sand.

Sedimentological characteristics are also affected by the erosional regime and channel pattern of the river. On the first $40-50 \mathrm{~km}$ it was originally anastomosing and accumulating, then for another $50-60 \mathrm{~km}$ a transitional section can be identified. After entering the Transdanubian Hills the river is flowing in a straight, incised channel for more than $200 \mathrm{~km}$. This section is prone to erosion especially in the loess covered region downstream of Budapest. The final $100 \mathrm{~km}$ is characterised by a meandering pattern, which was straightened at certain sections in the $19^{\text {th }}$ century (VITUKI, 1971; Mezösi, 2011). On its way through Hungary only smaller tributaries join the river, hardly changing the mineralogy of its sediment.

Sampling was made 2 months after the extreme flood of 2013, which activated connectivity and the transportation of sediments along the system. Consequently, samples were supposed to have higher $D_{\text {res }}$ than average. In all, 30 sites were visited (Fig. 1). Samples were collected from the bank (silt-clay) and the channel (sand) material, at each site from similar morphological position. Where it was possible, both silty-clayey (fine) and sandy (coarse) samples were collected. The fresh layer of sediments was easy to identify in case of both sample types (Fig. 2). Samples were collected into stainless steel cylinders (sand) or by taking and wrapping pieces of the topmost compact sediment layer (silty-clay).

\section{METHODS}

\section{Sample preparation}

Samples were dried and the outer $5 \mathrm{~mm}$ of both sand cores and silt flakes were removed. Coarse grain $(90-150 \mu \mathrm{m})$ and fine grain $(4-11 \mu \mathrm{m})$ samples were prepared by usual techniques. The separation of grain size fractions was made by wet sieving and settling in Atterberg cylinders, respectively. The carbonate and organic material content was removed by repeated treatment in $10 \% \mathrm{HCl}$ and $10 \% \mathrm{H}_{2} \mathrm{O}_{2}$. In case of coarse grains, a sodium polytungstate (LST Fastfloat) heavy liquid separation was applied for the separation of the quartz fraction. This step was followed by a $50 \mathrm{~min}$ etching in $40 \% \mathrm{HF}$. The abundance of quartz in fine grain samples was enhanced by a 7 day etching in hexafluorosilicic acid. Coarse grains were adhered to stainless steel discs by silicone spray $(6 \mathrm{~mm}$ mask for preheat and TT tests and $2 \mathrm{~mm}$ mask for $\mathrm{D}_{\text {res }}$ measurements), fine grains ( $2 \mathrm{mg} /$ aliquot) were settled on aluminium discs using acetone.

\section{Experimental details}

OSL measurements were made using a Risø TL-DA15 TL/OSL luminescence reader at the Szeged Luminescence Dating Laboratory. Tests and equivalent dose determination were based on the SAR protocol (Murray and Wintle, 2003).

From the total 30 sites, 5 sites (D5, D10, D21, D26, D30), representing the different morphological sections of the river (Fig. 1), were selected to perform detailed measurements, focusing on preheat and cutheat temperatures and TT on both fine and coarse grain samples.

First the response to different preheat and cutheat temperatures was tested in case of the selected samples. A combined dose recovery and preheat test was applied, starting with a repeated optical stimulation, followed by administering a known dose, and completed by SAR measurements using different combinations of preheat and cutheat temperatures. Preheat and cutheat temperatures were increased from $200^{\circ} \mathrm{C}$ to $260^{\circ} \mathrm{C}$ and $120^{\circ} \mathrm{C}$ to $180^{\circ} \mathrm{C}$, respectively, both in $20^{\circ} \mathrm{C}$ steps. Each temperature combination was applied on 5 aliquots.

For the TT tests, the procedure of Treulsen and Wallinga (2003) was adopted and modified. The test has two main phases (Table 1). In the first phase, after bleaching 5 aliquots and administering no artificial dose, OSL responses are measured by applying increasing preheat temperatures in ten cycles on each aliquot. The preheat activated equivalent dose is then determined by using 3 regeneration cycles (Table 1).

The aim of the second phase of TT tests was to determine the effect of simultaneous thermal and optical stimulation (hot bleach), and whether this type of treatment can mitigate the TT phenomenon experienced in the first phase of tests. Consequently, the previous measurement structure was applied on the same aliquots but by inserting an elevated temperature optical bleaching (Murray and Wintle, 2003) both before measuring preheat OSL responses and before each regeneration cycle (Table 1).

After evaluating the results of the preheat/cutheat tests and the detailed TT tests all other samples were subjected to a simplified TT test using the temperature settings which proved to be adequate for the $\mathrm{D}_{\mathrm{e}}$ measurements. 


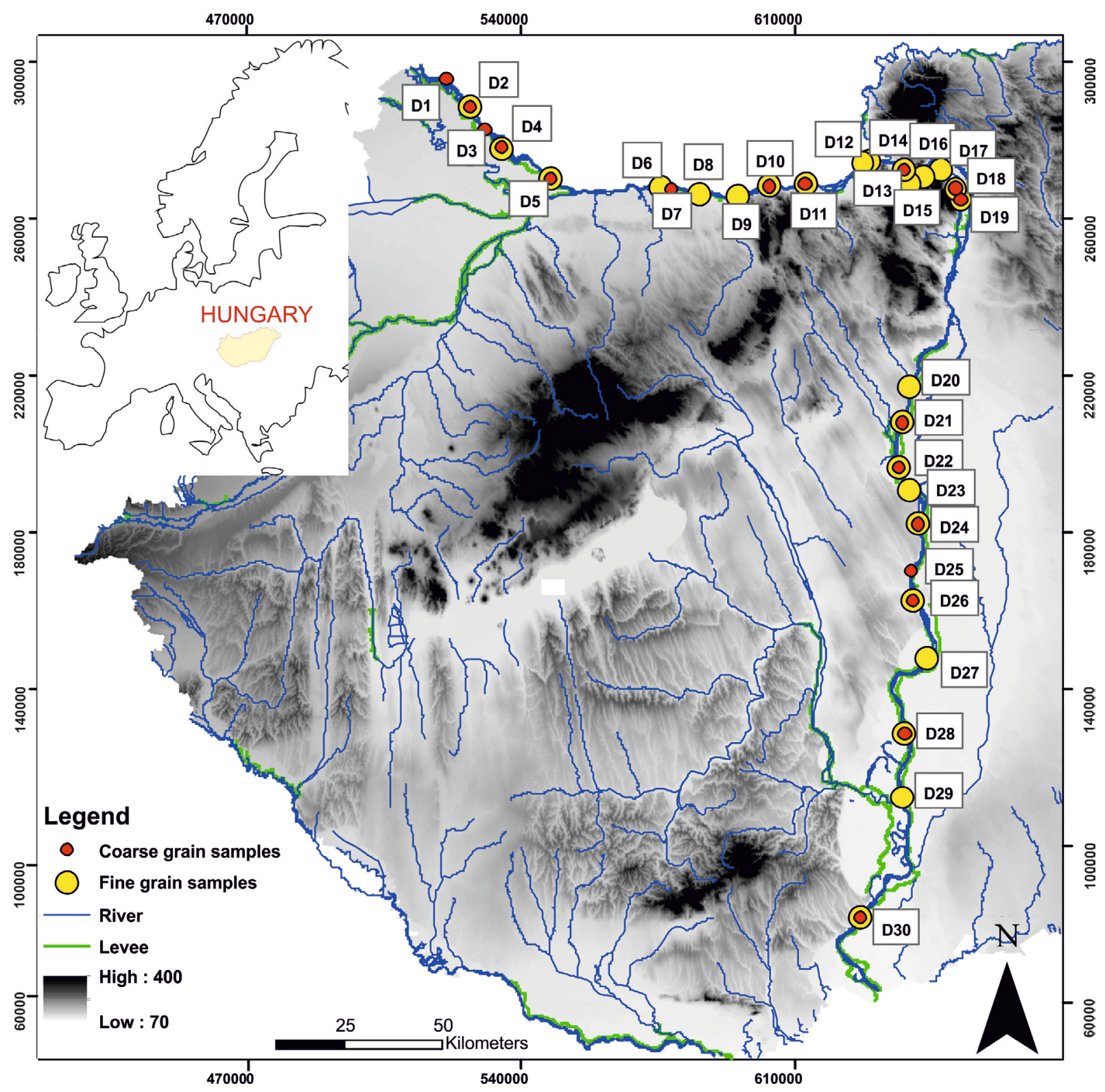

Fig. 1. The location of sampling sites along the Hungarian section of the Danube.

The measurement of sample $\mathrm{D}_{\mathrm{e}}$, and consequently $\mathrm{D}_{\text {res, }}$, was made using 48 and 24 aliquots in case of coarse grain and fine gain samples, respectively. Temperature settings were based on the tests above to minimise the effect of TT. The first $0.5 \mathrm{~s}$ of OSL curves was taken as the signal, the last $10 \mathrm{~s}$ were used to estimate the background of measurements. Possible feldspar contamination was also monitored by measuring IRSL/OSL depletion ratio at the end of the SAR procedure. Coarse grain sample $\mathrm{D}_{\mathrm{e}}$ was determined by using the un-logged minimum age model (Galbraight et al., 1999). In case of fine grain samples, the arithmetic mean and standard error of individual results was taken as $\mathrm{D}_{\mathrm{e}}$.

\section{RESULTS AND DISCUSSION}

\section{Preheat-cutheat tests}

Concerning the samples tested in detail, recycling ratios exhibited a large scatter throughout the test as a consequence of the relatively low sensitivity and rather poor luminescence response of both coarse and fine grain samples. Recuperation increased usually at $240^{\circ} \mathrm{C}$ in case of coarse grain aliquots, but remained constantly low for fines (Fig. 3). As expected, given doses were recovered better by fine grain samples, however there were several temperature combinations where coarse grain aliquots performed well, too (Fig. 3). When the three criteria 

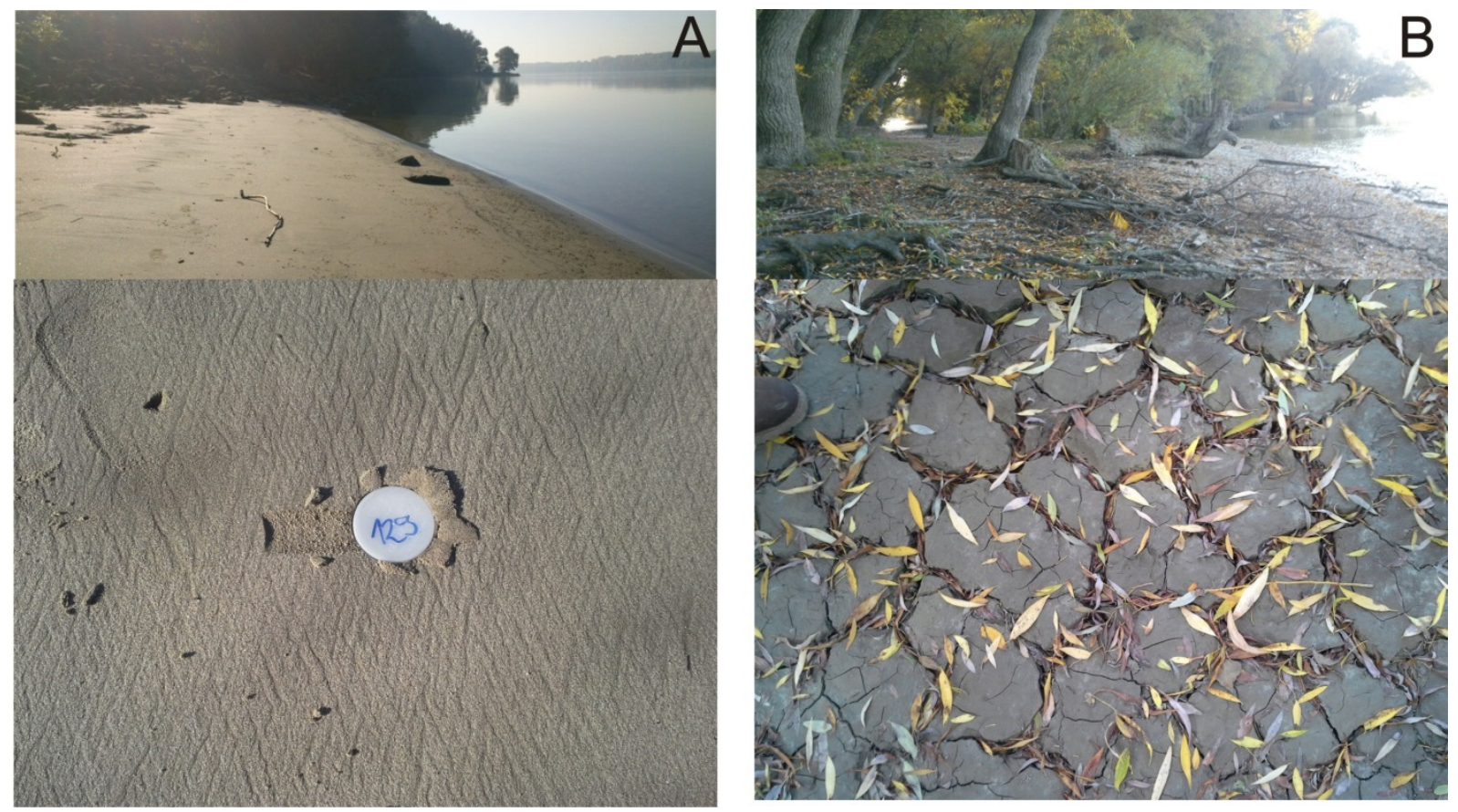

Fig. 2. Sandy coarse (A) and silty-clayey fine (B) sediments deposited by the 2013 flood.

Table 1. The arrangement and measurement parameters of the two phase TT test (phase 1 adopted from Truelsen and Wallinga, 2003).

\begin{tabular}{|c|c|c|c|c|}
\hline Step & \multicolumn{2}{|c|}{ TT test, phase 1} & \multicolumn{2}{|c|}{ TT test, phase 2} \\
\hline pre & $\begin{array}{c}\text { Optical bleaching } \\
\left(\text { Stimulation } 200 \mathrm{~s} \text { at } 120^{\circ} \mathrm{C}\right)\end{array}$ & & & \\
\hline 1 & & & $\begin{array}{l}\text { Optical and thermal bleaching } \\
\text { (Stimulation } 200 \mathrm{~s} \text { at } 280^{\circ} \mathrm{C} \text { ) }\end{array}$ & $\begin{array}{l}\text { Optical and thermal bleaching } \\
\text { (Stimulation } 200 \mathrm{~s} \text { at } 280^{\circ} \mathrm{C} \text { ) }\end{array}$ \\
\hline 2 & - & $\begin{array}{l}\text { Regeneration doses } \\
(0.8-1.7-2.5 \mathrm{~Gy})\end{array}$ & & $\begin{array}{l}\text { Regeneration doses } \\
(0.8-1.7-2.5 \mathrm{~Gy})\end{array}$ \\
\hline 3 & $\begin{array}{c}\text { Preheat } \\
\left(120-300^{\circ} \mathrm{C}, 20^{\circ} \mathrm{C} \text { steps }\right)\end{array}$ & $\begin{array}{l}\text { Preheat } \\
\left(200^{\circ} \mathrm{C}\right) \\
\end{array}$ & $\begin{array}{c}\text { Preheat } \\
\left(120-300^{\circ} \mathrm{C}, 20^{\circ} \mathrm{C} \text { steps }\right)\end{array}$ & $\begin{array}{l}\text { Preheat } \\
\left(200^{\circ} \mathrm{C}\right) \\
\end{array}$ \\
\hline 4 & $\begin{array}{c}\text { OSL measurement } \\
\left(\text { Stimulation } 40 \mathrm{~s} \text { at } 125^{\circ} \mathrm{C}\right)\end{array}$ & $\begin{array}{c}\text { OSL measurement } \\
\left.\text { (Stimulation } 40 \mathrm{~s} \text { at } 125^{\circ} \mathrm{C}\right)\end{array}$ & $\begin{array}{c}\text { OSL measurement } \\
\text { (Stimulation } 40 \mathrm{~s} \text { at } 125^{\circ} \mathrm{C} \text { ) }\end{array}$ & $\begin{array}{c}\text { OSL measurement } \\
\left.\text { (Stimulation } 40 \mathrm{~s} \text { at } 125^{\circ} \mathrm{C}\right)\end{array}$ \\
\hline 5 & $\begin{array}{l}\text { Test dose } \\
\text { (1.7 Gy) }\end{array}$ & $\begin{array}{c}\text { Test dose } \\
\text { (1.7 Gy) }\end{array}$ & $\begin{array}{l}\text { Test dose } \\
\text { (1.7 Gy) }\end{array}$ & $\begin{array}{l}\text { Test dose } \\
\text { (1.7 Gy) }\end{array}$ \\
\hline 6 & $\begin{array}{l}\text { Cutheat } \\
\left(160^{\circ} \mathrm{C}\right)\end{array}$ & $\begin{array}{l}\text { Cutheat } \\
\left(160^{\circ} \mathrm{C}\right)\end{array}$ & $\begin{array}{l}\text { Cutheat } \\
\left(160^{\circ} \mathrm{C}\right)\end{array}$ & $\begin{array}{l}\text { Cutheat } \\
\left(160^{\circ} \mathrm{C}\right)\end{array}$ \\
\hline 7 & $\begin{array}{c}\text { OSL measurement } \\
\text { (Stimulation } 40 \mathrm{~s} \text { at } 125^{\circ} \mathrm{C} \text { ) }\end{array}$ & $\begin{array}{c}\text { OSL measurement } \\
\left.\text { (Stimulation } 40 \mathrm{~s} \text { at } 125^{\circ} \mathrm{C}\right)\end{array}$ & $\begin{array}{c}\text { OSL measurement } \\
\left(\text { Stimulation } 40 \mathrm{~s} \text { at } 125^{\circ} \mathrm{C}\right)\end{array}$ & $\begin{array}{c}\text { OSL measurement } \\
\text { (Stimulation } 40 \mathrm{~s} \text { at } 125^{\circ} \mathrm{C} \text { ) }\end{array}$ \\
\hline
\end{tabular}

(recycling ratio, recuperation, dose recovery) were considered together, the $200^{\circ} \mathrm{C} / 160^{\circ} \mathrm{C}$ preheat-cutheat treatment proved to be the best option. At this temperature combination the average recycling ratio, recuperation and dose recovery ratio of samples investigated in detail were $1.02 \pm 0.04,2.58 \%$ and $0.98 \pm 0.05$ for the coarse grain and $1.03 \pm 0.05,0.17 \%$ and $0.99 \pm 0.11$ for the fine grain fraction, respectively.

\section{Thermal transfer}

In the first phase of the tests, coarse grain results exhibited the same pattern concerning TT in case of almost each sample. Regarding measurements without hot bleach (w/oHB) TT is insignificant at low temperatures and even negative values appear, which is due to the fact that practically no signal was detected subsequent to thermal treatment at low temperatures. An inflection point can be identified at $180-200^{\circ} \mathrm{C}$, over which the gradual increase of TT values starts, which corresponds well to the findings made at the preheat-cutheat tests. The mean value of TT at $200^{\circ} \mathrm{C}$ is $0.06 \pm 0.05$ Gy with a maximum value of $0.25 \pm 14$ Gy. Regarding the 5 samples only one, sample D26 exhibited practically no transfer effects in the high temperature region (Fig. 4). The mean TT of the 5 sam- 

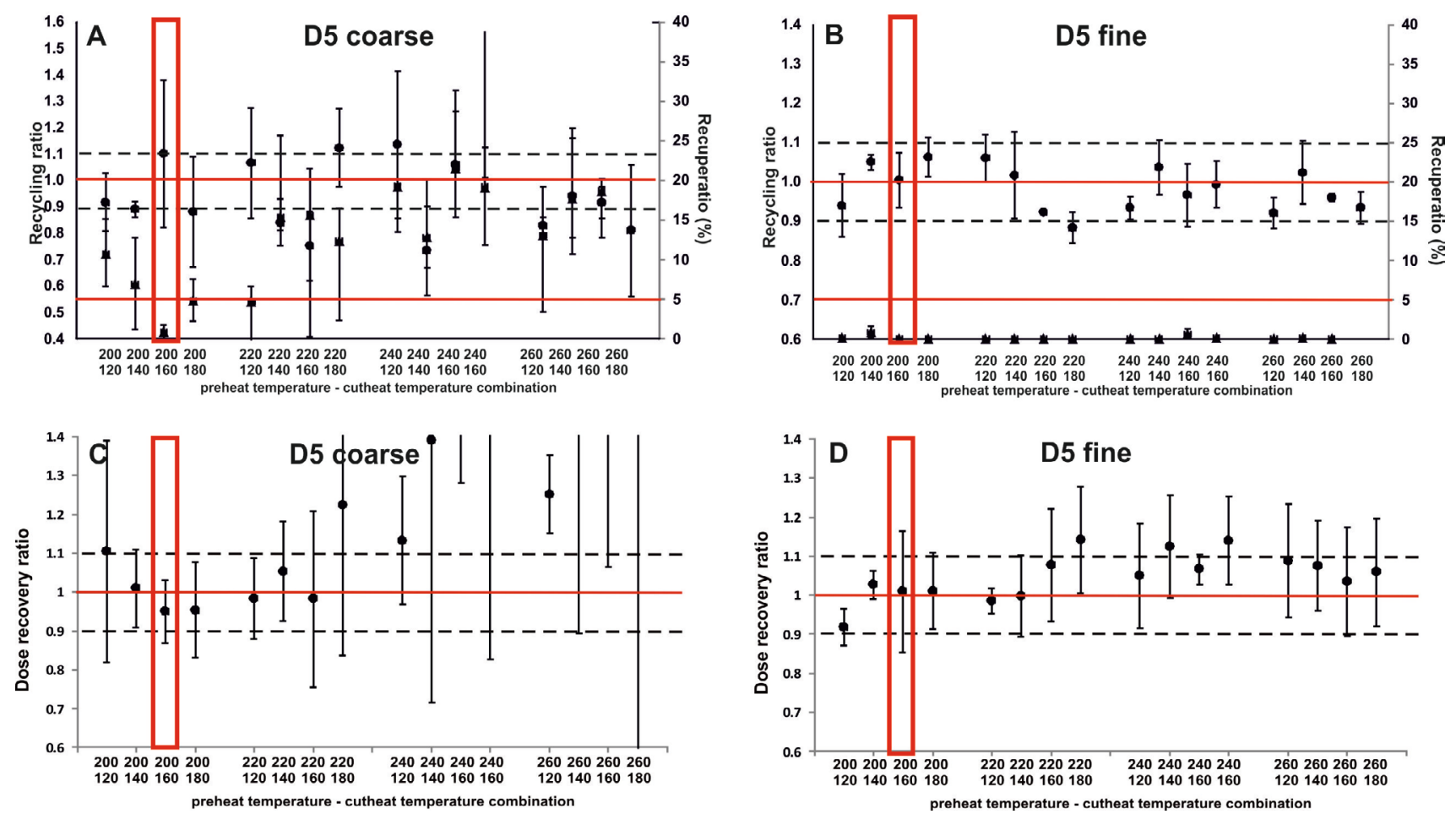

Fig. 3. Results of the preheat-cutheat test on sample D5/coarse, and D5/fine. A) and B) recycling ratio and recuperation, $C$ ) and D) dose recovery ratio. Each point is the average of 3 aliquots, error bars refer to the standard error of results.

ples at $300^{\circ} \mathrm{C}$ was therefore $0.88 \pm 0.33 \mathrm{~Gy}$. Concerning the second phase of TT tests, when measurements were made with a hot bleach $(\mathrm{w} / \mathrm{HB}) \mathrm{TT}$ values were stable. This meant that even at low temperatures some TT occurred and similar values were characteristic in the entire temperature range (Fig. 4). Consequently, at $200^{\circ} \mathrm{C}$ and $300^{\circ} \mathrm{C}$ the mean value of TT was $0.65 \pm 0.22 \mathrm{~Gy}$ (maximum value: $1.17 \pm 0.19 \mathrm{~Gy}$ ) and $0.68 \pm 0.20 \mathrm{~Gy}$, respectively, meaning that in both cases $\mathrm{w} / \mathrm{HB}$ values exceeded w/oHB values by $0.1 \mathrm{~Gy}$.

In terms of fine grain samples, w/oHB values of TT showed a similar pattern than in case of coarse grain samples, however results were in general lower and the difference between lower and higher temperature values was smaller (Fig. 4). The mean TT at $200^{\circ} \mathrm{C}$ was $-0.07 \pm 0.03$ with a maximum value of $0.00 \pm 0.01 \mathrm{~Gy}$, in the meantime TT at $300^{\circ} \mathrm{C}$ was $0.18 \pm 0.03 \mathrm{~Gy}$. When measurements were made $\mathrm{w} / \mathrm{HB}$ the experienced TT values were remarkably higher than w/oHB results (Fig. 4). On average, the degree of $\mathrm{w} / \mathrm{HB} \mathrm{TT}$ at $200^{\circ} \mathrm{C}$ was $0.94 \pm 0.02$ Gy with a maximum value of $0.99 \pm 0.04 \mathrm{~Gy}$. Accordingly, mean TT at $300^{\circ} \mathrm{C}$ was $0.94 \pm 0.02$ Gy. Consequently, in all w/HB TT was higher than w/oHB TT regarding fine grain samples, just like in terms of coarse grain samples. When coarse and fine grain results are compared it is also obvious that TT is significantly lower in case of fines if measurements are done w/oHB. The mean TT values received are similar to those measured by Truelsen and Wallinga (2003) at $200^{\circ} \mathrm{C}(\sim 0.2 \mathrm{~Gy})$.
Finally, all coarse and fine grain samples were tested for TT. Measurements were carried out without applying $\mathrm{HB}$, using a $200^{\circ} \mathrm{C}$ and $160^{\circ} \mathrm{C}$ preheat and cutheat temperature, respectively. In general, the results of fine grain samples were lower (average: $-0.02 \pm 0.00 \mathrm{~Gy}$; max: $0.04 \pm 0.01 \mathrm{~Gy}$ ) than those of coarse grains (average: $0.04 \pm 0.00$ Gy; max: $0.25 \pm 0.14$ Gy).

There is no obvious trend or pattern, if sample TT results are plotted on the longitudinal section of the river (Fig. 5). Values are usually low with some outstanding peaks, but these cannot be related to any of the tributaries or morphological change of the Danube itself. Accordingly, the mineralogical characteristics of quartz should be fairly uniform along the investigated section. As a matter of the low values experienced above, it seems that TT correction during routine $D_{e}$ measurements is not necessary, and Danube sediments perform in this respect well on the investigated section. The level of TT in the present study is very close to that of Jaiswal et al. (2009) and Truelsen and Wallinga (2003).

\section{Residual doses}

Following tests on TT, $\mathrm{D}_{\text {res }}$ was determined for each coarse and fine grain sample. In case the value of TT was positive $D_{\text {res }}$ was calculated by subtracting the TT dose from the measured $D_{e}$ (Table 2). The corrected results were considered as the apparent $\mathrm{D}_{\text {res }}$ of samples. 



Fig. 4. Thermal transfer in coarse and fine grain samples at different temperatures. 
Table 2. Equivalent dose, thermal transfer and corrected residual dose of the investigated modern samples.

\begin{tabular}{|c|c|c|c|c|c|c|c|}
\hline \multirow[b]{2}{*}{$\begin{array}{l}\text { Sample } \\
\text { ID }\end{array}$} & \multirow[b]{2}{*}{ river km } & \multicolumn{3}{|c|}{ coarse grain } & \multicolumn{3}{|c|}{ fine grain } \\
\hline & & $\begin{array}{l}D_{e} \\
(G y)\end{array}$ & $\begin{array}{c}\text { TT } \\
\text { (Gy) }\end{array}$ & $\begin{array}{l}\text { Dres } \\
(G y)\end{array}$ & $\begin{array}{l}D_{e} \\
(G y)\end{array}$ & $\begin{array}{l}\text { TT } \\
\text { (Gy) }\end{array}$ & $\begin{array}{l}D_{\text {res }} \\
(G y)\end{array}$ \\
\hline D1 & 1835 & $0.20 \pm 0.21$ & $0.03 \pm 0.04$ & $0.18 \pm 0.21$ & & & \\
\hline D2 & 1830 & $0.24 \pm 0.17$ & $0.04 \pm 0.06$ & $0.20 \pm 0.18$ & $1.65 \pm 0.46$ & $-0.02 \pm 0.01$ & $1.65 \pm 0.46$ \\
\hline D3 & 1825 & $0.26 \pm 0.17$ & $0.01 \pm 0.03$ & $0.24 \pm 0.17$ & & & \\
\hline D4 & 1820 & $0.08 \pm 0.15$ & $0.08 \pm 0.05$ & $0.00 \pm 0.16$ & $0.56 \pm 0.04$ & $-0.03 \pm 0.01$ & $0.56 \pm 0.04$ \\
\hline D5 & 1801 & $0.07 \pm 0.06$ & $0.25 \pm 0.14$ & $0.00 \pm 0.15$ & $0.43 \pm 0.04$ & $-0.08 \pm 0.02$ & $0.43 \pm 0.04$ \\
\hline D6 & 1772 & & & & $0.67 \pm 0.12$ & $-0.01 \pm 0.01$ & $0.67 \pm 0.12$ \\
\hline D7 & 1768 & $0.27 \pm 0.27$ & $0.04 \pm 0.03$ & $0.23 \pm 0.27$ & & & \\
\hline D8 & 1765 & & & & $0.37 \pm 0.05$ & $0.02 \pm 0.01$ & $0.35 \pm 0.05$ \\
\hline D9 & 1755 & & & & $0.86 \pm 0.06$ & $-0.01 \pm 0.01$ & $0.86 \pm 0.06$ \\
\hline D10 & 1750 & $0.04 \pm 0.04$ & $0.04 \pm 0.03$ & $0.00 \pm 0.05$ & $0.98 \pm 0.09$ & $-0.17 \pm 0.05$ & $0.98 \pm 0.09$ \\
\hline D11 & 1725 & $0.05 \pm 0.08$ & $0.00 \pm 0.06$ & $0.05 \pm 0.10$ & $0.46 \pm 0.05$ & $-0.07 \pm 0.01$ & $0.46 \pm 0.05$ \\
\hline D12 & 1715 & & & & $0.27 \pm 0.04$ & $-0.02 \pm 0.01$ & $0.27 \pm 0.04$ \\
\hline D13 & 1712 & & & & $0.88 \pm 0.12$ & $0.00 \pm 0.01$ & $0.88 \pm 0.12$ \\
\hline D14 & 1700 & $0.56 \pm 0.34$ & $0.05 \pm 0.12$ & $0.52 \pm 0.36$ & $0.63 \pm 0.09$ & $0.03 \pm 0.01$ & $0.60 \pm 0.09$ \\
\hline D15 & 1696 & & & & $1.59 \pm 0.27$ & $0.01 \pm 0.00$ & $1.59 \pm 0.27$ \\
\hline D16 & 1690 & & & & $0.61 \pm 0.04$ & $0.00 \pm 0.01$ & $0.61 \pm 0.04$ \\
\hline D17 & 1684 & & & & $1.03 \pm 0.10$ & $-0.05 \pm 0.01$ & $1.03 \pm 0.10$ \\
\hline D18 & 1675 & $0.08 \pm 0.05$ & $0.03 \pm 0.02$ & $0.06 \pm 0.06$ & $0.77 \pm 0.09$ & $-0.02 \pm 0.01$ & $0.77 \pm 0.09$ \\
\hline D19 & 1670 & $0.05 \pm 0.04$ & $0.00 \pm 0.04$ & $0.05 \pm 0.06$ & $1.96 \pm 0.26$ & $0.04 \pm 0.01$ & $1.92 \pm 0.26$ \\
\hline D20 & 1610 & & & & $0.63 \pm 0.10$ & $-0.06 \pm 0.01$ & $0.63 \pm 0.10$ \\
\hline D21 & 1600 & $0.07 \pm 0.04$ & $0.01 \pm 0.01$ & $0.07 \pm 0.04$ & $1.27 \pm 0.07$ & $-0.08 \pm 0.03$ & $1.27 \pm 0.07$ \\
\hline D22 & 1597 & $0.17 \pm 0.20$ & $0.04 \pm 0.01$ & $0.13 \pm 0.20$ & $3.18 \pm 0.16$ & $-0.03 \pm 0.01$ & $3.18 \pm 0.16$ \\
\hline D23 & 1592 & & & & $14.52 \pm 0.52$ & $0.03 \pm 0.01$ & $14.50 \pm 0.52$ \\
\hline D24 & 1570 & $0.03 \pm 0.05$ & $0.04 \pm 0.04$ & $-0.01 \pm 0.06$ & & & \\
\hline D25 & 1565 & $0.09 \pm 0.11$ & $-0.02 \pm 0.01$ & $0.09 \pm 0.11$ & $2.37 \pm 0.17$ & $0.01 \pm 0.00$ & $2.36 \pm 0.17$ \\
\hline D26 & 1560 & $0.04 \pm 0.04$ & $0.03 \pm 0.06$ & $0.01 \pm 0.07$ & $7.55 \pm 0.35$ & $0.00 \pm 0.01$ & $7.55 \pm 0.35$ \\
\hline D27 & 1545 & & & & $13.11 \pm 0.96$ & $0.04 \pm 0.01$ & $13.07 \pm 0.96$ \\
\hline D28 & 1535 & $0.16 \pm 0.16$ & $0.00 \pm 0.05$ & $0.16 \pm 0.17$ & $2.50 \pm 0.83$ & $0.02 \pm 0.01$ & $2.48 \pm 0.83$ \\
\hline D29 & 1522 & & & & $0.87 \pm 0.03$ & $0.02 \pm 0.01$ & $0.85 \pm 0.03$ \\
\hline D30 & 1510 & $0.07 \pm 0.10$ & $-0.01 \pm 0.11$ & $0.07 \pm 0.10$ & $1.25 \pm 0.03$ & $-0.01 \pm 0.04$ & $1.25 \pm 0.03$ \\
\hline
\end{tabular}

Concerning coarse grain samples mean and maximum $\mathrm{D}_{\text {res }}$ was $0.10 \pm 0.01 \mathrm{~Gy}$ and $0.56 \pm 0.17 \mathrm{~Gy}$, respectively, whereas in case of fine grain samples the mean and maximum reached $2.34 \pm 0.72$ Gy and $14.50 \pm 0.52$ Gy. Consequently, $\mathrm{D}_{\text {res }}$ was almost negligible in case of coarse grain samples equaling to a $60-120$ y age overestimation if usual 1.0-2.0 Gy/ky dose rates are considered. As it was shown in numerous previous studies $\mathrm{D}_{\text {res }}$ of fine grain samples is considerably higher, leading to an average 1.2-2.3 ky age overestimation (Table 2).

If results are considered longitudinally along the investigated section of the river, coarse grain values do not exhibit any spatial tendencies or patterns. There is one outstanding value, but it cannot be related to any change in morphology or fluvial dynamics. On the contrary, in terms of fine grain samples a sharp increase can be observed on the downstream half of the studied Danube reach. The increasing tendency starts upstream of Budapest, where the river has an incising character. The great- est values $(14.5 \pm 0.5$ and $13.1 \pm 1.0 \mathrm{~Gy})$ appear however more downstream at sampling points D23 and D27. Further on, the values decrease again. This refers to a local but significant disturbance in fine grain $\mathrm{D}_{\text {res }}$ values (Fig. 6). The clearly identifiable phenomenon is apparent at locations downstream of erodible loess bluffs along the right bank of the river (Fig. 8). It is suggested therefore that Pleistocene sediments transferred to the Danube as a consequence of flood-time fluvial erosion and almost continuous mass movements can significantly contribute to residual doses. The above finding is also supported by the fact that coarse grain $D_{\text {res }}$ values do not show any increase at these sites, thus very likely the source of $D_{\text {res }}$ disturbance is loess. The gradual decrease of fine grain $D_{\text {res }}$ values downstream of the erosional section also shows how bleaching affects the fine grain suspended load of the river, as such, in $20 \mathrm{~km}$ the level of $\mathrm{D}_{\text {res }}$ drops to similar values as on the upstream half of the investigated Danube reach (Fig. 7). 


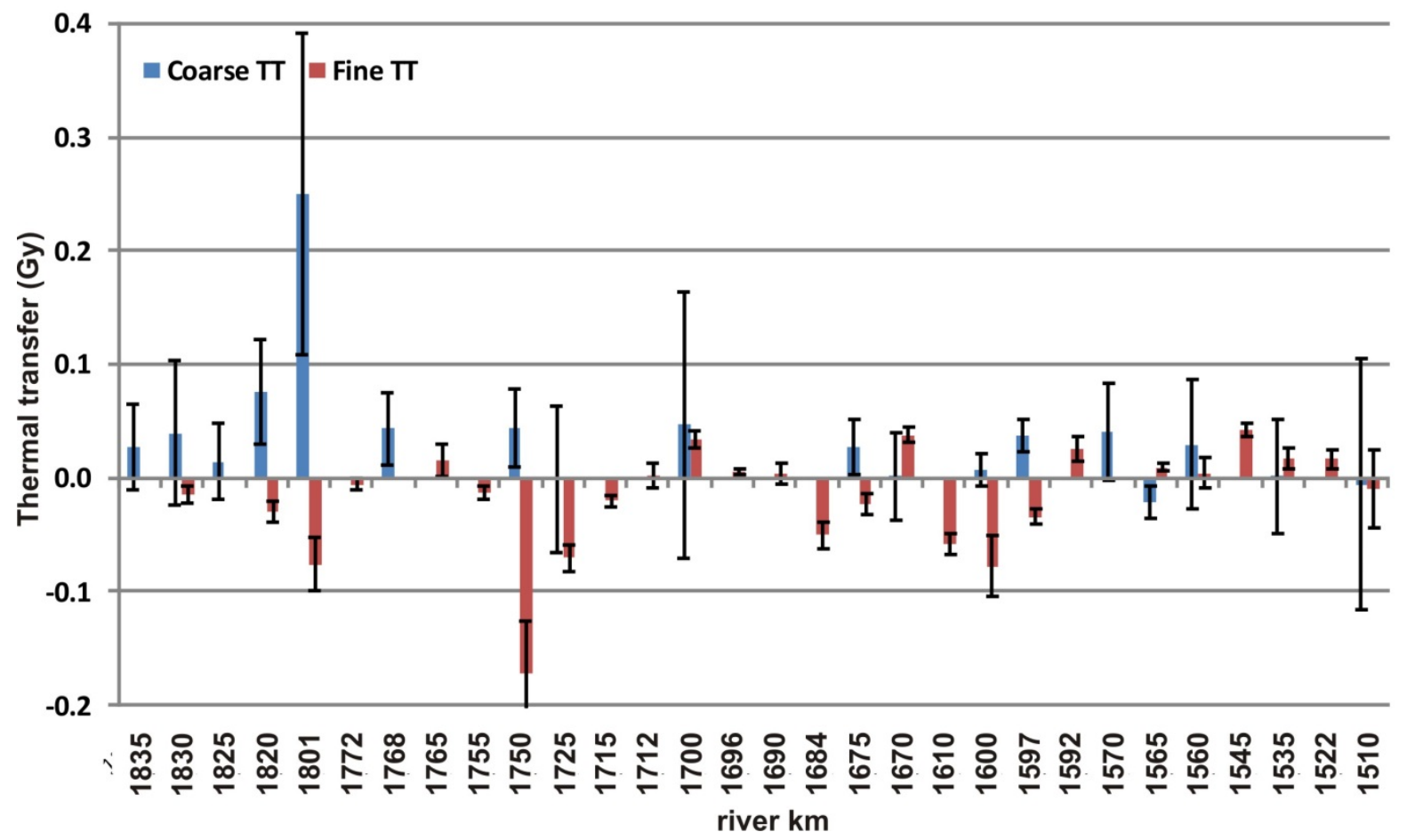

Fig. 5. The values of coarse and fine grain TT along the investigated longitudinal section of the Danube.

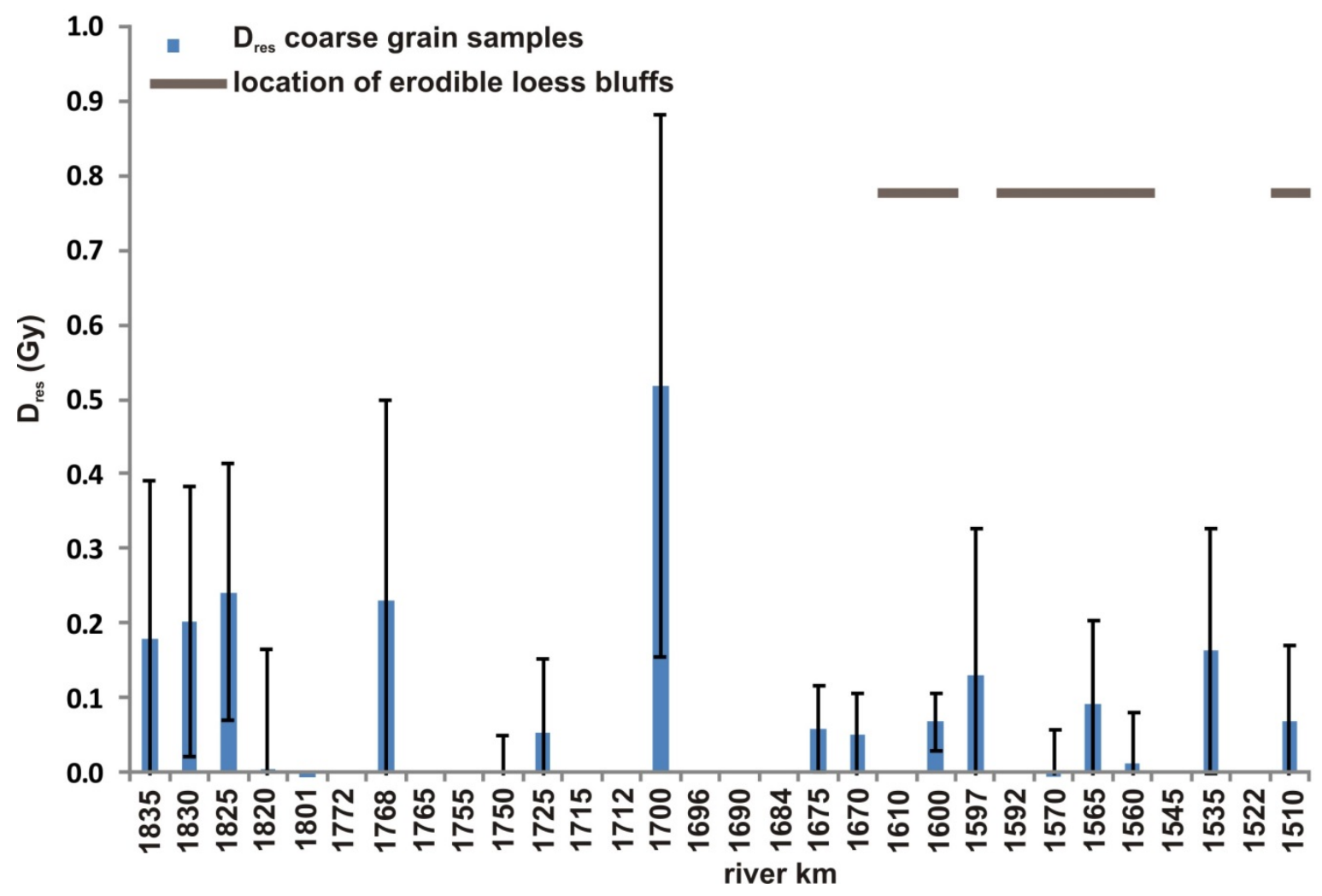

Fig. 6. The residual dose in modern coarse grain sediments along the investigated river reach of the Danube. 


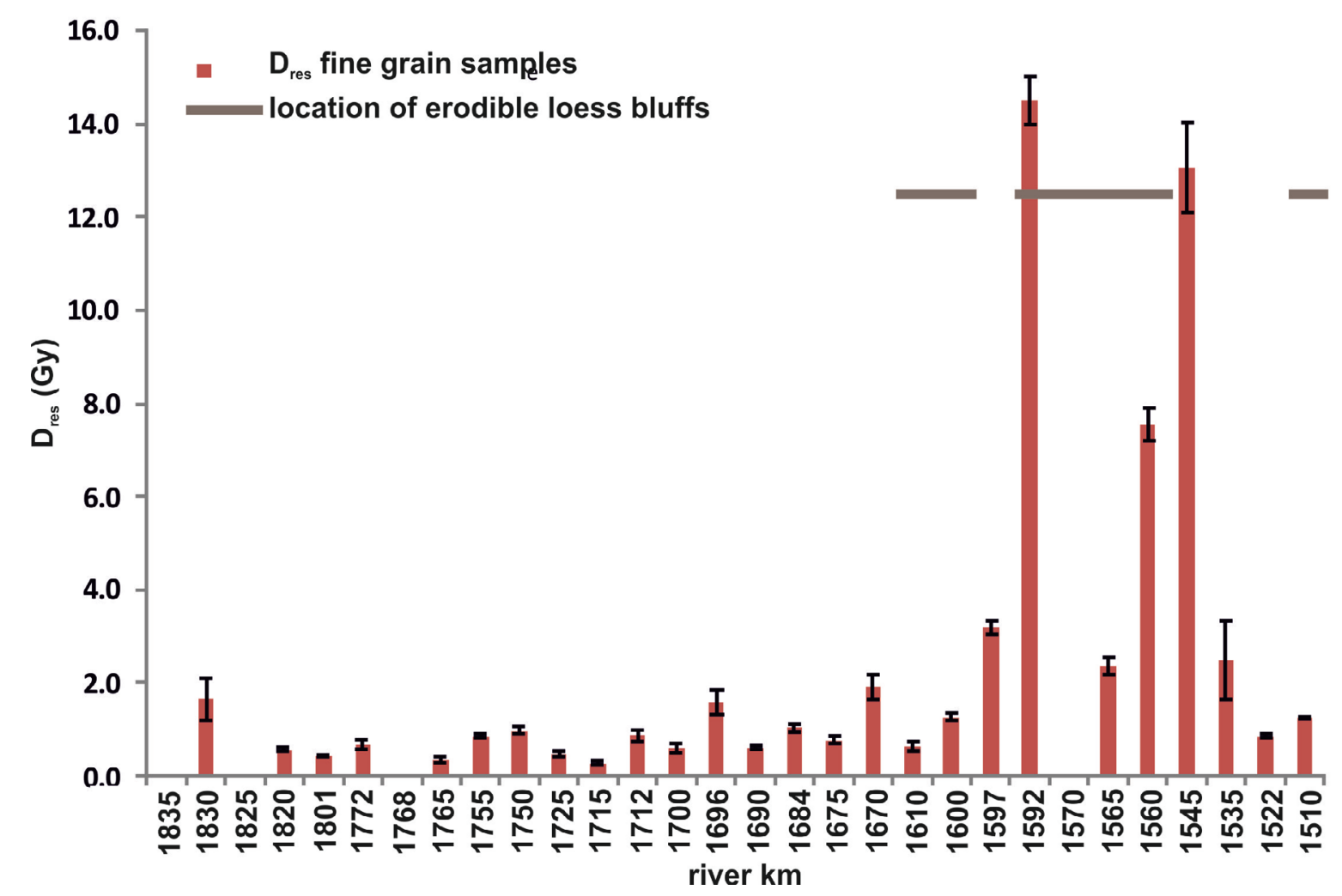

Fig. 7. The residual dose in modern fine grain sediments along the investigated river reach of the Danube.

\section{CONCLUSION}

In the present study, the contribution of thermal transfer and incomplete bleaching to equivalent doses measured in terms of modern fluvial samples was investigated. Tests on both coarse and fine grain sediments proved that as a matter of TT, the virtual equivalent dose of Danube sediments increases considerably if preheat temperature is set above $200^{\circ} \mathrm{C}$. Fine grain samples exhibited a more uniform pattern of TT at different preheat temperatures, whereas coarse grain samples showed a higher variability. Although the use of a HB decreases the scatter of recovered doses, it also introduces a considerable degree of TT, which differs from sample to sample. Therefore, the w/oHB SAR protocol is advised to be used in subsequent studies processing Hungarian Danube sediments. In general, the TT of samples was not considerable, and correction seems to be necessary only in case of modern and few centuries old sediments. Concerning coarse grain young sediments therefore a $0.04 \pm 0.00$ Gy TT correction value is suggested on the basis of the present study.

Bleaching of medium sand sized coarse grain sediments is fairly complete along the investigated river reach, consequently the mean and standard error of $D_{\text {res }}$ is $0.10 \pm 0.01$ Gy. Therefore, it is suggested that regarding younger sediment deposits from the investigated area $D_{e}$ results should be corrected by this value. Besides, in terms of Danube related palaeo-sediments the effect of incomplete bleaching on the measured $D_{e}$ seems to be of low significance if a proper statistical treatment is applied, however the depositional environment might cause some differences which should be investigated further in the future.

As expected, concerning fine grain sediments incomplete bleaching can be considerable, the mean and standard error of fine grain $D_{\text {res }}$ along the studied section of the river is $2.34 \pm 0.72 \mathrm{~Gy}$. The longitudinal pattern of values shows a great contrast, implying that on the lower reaches this fraction cannot be applied safely for palaeosediments in the usual age range of fine grain quartz OSL dating. However, on the upstream part of the studied section in depositional environments where no sand is available fine grains can be an alternative over the age range of several thousands of years, however, $D_{\text {res }}$ must be considered and the mean value received here $(0.85 \pm 0.12 \mathrm{~Gy})$ must be indicated.

The longitudinal distribution of $\mathrm{D}_{\text {res }}$ in case of coarse grain modern sediments showed no clear pattern or tendency, however, regarding fine grain sediments an unambiguous increase was revealed at sections where the Danube is passing loess bluffs. This way it is suggested that fine grain $D_{\text {res }}$ can be an indicator of modern day erosional activity. 




Fig. 8. The location of erodible loess bluffs and sampling points along the downstream part of the investigated Danube reach.

\section{ACKNOWLEDGEMENTS}

This research was funded by the following projects: NKFI K 119309, NKFI K 119193 and HURO/1101/126/2.2.1 ENVIARCH.

\section{REFERENCES}

Aitken MJ, 1998. An Introduction to Optical Dating. Oxford University Press. London.

Alexanderson H, 2007. Residual OSL signals from modern Greenlandic river sediments. Geochronometria 26: 1-9, DOI 10.2478/v10003007-0001-6.
Bogárdi J, 1971. Sediment transport of streams. Academic Press, Budapest.

Colls AE, Stokes S, Blum MD and Straffin E, 2001. Age limits on the Late Quaternary evolution of the upper Loire River. Quaternary Science Reviews 20: 743-750, DOI 10.1016/S02773791(00)00048-2.

Fiebig M and Preusser F, 2007. Investigating the amount of zeroing in modern sediments of River Danube, Austria. Quaternary Geochronology 2: 143-149, DOI 10.1016/j.quageo.2006.09.001.

Fuchs $\mathrm{M}$ and Lang A, 2001. OSL dating of coarse-grain fluvial quartz using single-aliquot protocols on sediments from NE Peloponnese, Greece. Quaternary Science Reviews 20: 783-787, DOI 10.1016/S0277-3791(00)00040-8.

Galbraith RF, 2005. Statistics for Fission Track Analysis. 240. p. Chapman and Hall, London. 
Galbraith RF, Roberts RG, Laslett GM, Yoshida H and Olley JM, 1999. Optical dating of single and multiple grains of quartz from Jinmium rock shelter, northern Australia. Part I: Experimental design and statistical models. Archeometry 41: 339-364, DOI 10.1111/j.1475-4754.1999.tb00987.x.

Hu G, Zhang J-F, Qui W-L and Zhou L-P, 2010. Residual OSL signals in modern fluvial sediments from Yellow River (HuangHe) and the implications for dating young sediments. Quaternary Geochronology 5: 187-193, DOI 10.1016/j.quageo.2009.05.003.

Jain M, Thomsen KJ, Botter-Jensen L and Murray AS, 2004. Thermal transfer and apparent-dose distribution in poorly bleached mortar samples: Results from single grains and small aliquots of quartz. Radiation Measurements 38: 101-109, DOI 10.1016/j.radmeas.2003.07.002.

Jaiswal MK, Chen YG, Kale VS and Achyuthan H, 2009. Residual luminescence in quartz from slack water deposits in Kaveri Basin, South India: a single aliquot approach. Geocronometria 33: 1-8, DOI 10.2478/v10003-009-0009-1.

Lepper K, Larsen NA and McKeever SWS, 2000. Equivalent dose distribution analysis of Holocene eolian and fluvial quartz sands from central Oklahoma. Radiation Measurements 32: 603-608, DOI 10.1016/S1350-4487(00)00093-7.

Li B and Li S-H, 2006. Correcting for thermal transfer in OSL measurements of young sediment samples. Radiation Measurements 41: 855-861, DOI 10.1016/j.radmeas.2006.04.008.

Mezősi G, 2011. Geography of Hungary. Academic Press, Budapest.

Murray AS, Olley JM and Caitcheon GG, 1995. Measurements of equivalent doses in quartz from contemporary water-lain sediments using optically stimulated luminescence. Quaternary Science Reviews 14: 365-371, DOI 10.1016/0277-3791(95)00030-5.

Murray AS and Wintle AG, 2003. The single aliquot regenerative dose protocol: potential for improvements in reliability. Radiation Measurements 37(4): 377-381, DOI 10.1016/S13504487(03)00053-2.

Olley J, Caitcheon G and Murray A, 1998. The distribution of apparent dose as determined by optically stimulated luminescence in small aliquots of fluvial quartz: Implications for dating young sediments.
Radiation Measurements 30: 207-217, DOI 10.1016/S02773791(97)00090-5.

Rittenour TM, 2008. Luminescence dating of fluvial deposits: applications to geomorphic palaeoseismic and archaeological research. Boreas 37: 613-635, DOI 10.1111/j.1502-3885.2008.00056.x.

Sipos G, Kiss T and Tóth O, 2016. Constraining the age of floodplain levels along the lower section of River Tisza, Hungary. Journal of Environmental Geography 9(1-2): 39-44.

Stokes S, Bray HE and Blum MD, 2001. Optical resetting in large drainage basins: tests of zeroing assumptions using single-aliquot procedures. Quaternary Science Reviews 20: 879-885, DOI 10.1016/S0277-3791(00)00045-7.

Treulsen JL and Wallinga J, 2003. Zeroing of the OSL signal as a function of grain size: investigatting bleaching and thermal transfer for a young fluvial sample. Geochronometria 22: 1-8.

Vandenberghe D, Derese C and Houbrechts G, 2007. Residual doses in recent alluvial sediments from Ardenne (S Belgium). Geochronometria 28: 1-8, DOI 10.2478/v10003-007-0024-z.

VITUKI - Vízgazdálkodási Tudományos Kutató Intézet (Hungarian Water Resources Research Centre), 1971. Hydrographic Atlas Series 11. Danube 4. (Hydrography, geomorphology). Budapest.

Wallinga J, Murray AS, Duller GAT, Törnqvist TR, 2001. Testing optically stimulated luminescence dating of sand-sized quartz and feldspar from fluvial deposits. Earth and Planetery Science Letters 193: 617-630, DOI 10.1016/S0012-821X(01)00526-X.

Wang XL, Wintle AG and Lu YC, 2006. Thermally transferred luminescence in fine-grained quartz from Chinese loess: Basic observations. Radiation Measurements 41: 649-658, DOI 10.1016/j.radmeas.2006.01.001.

Ward S, Stokes S, Bailey R, Singarayer J, Goudie A and Bray H, 2003. Optical dating of quartz from young samples and the effects of pre-heat temperature. Radiation Measurements 37: 401-407, DOI 10.1016/S1350-4487(03)00004-0.

Wintle AG and Murray AS, 2006. A review of quartz optically stimulated luminescence characteristics and their relevance in singlealiquot regeneration dating protocols. Radiation Measurements 41: 369-391, DOI 10.1016/j.radmeas.2005.11.001. 